\title{
Cooperative Cataloging: Prospects and Problems for Libraries in Saudi Arabia
}

\section{Zahiruddin Khurshid}

Despite witnessing the enormous success of cooperative cataloging programs in Europe and North America, the libraries in Saudi Arabia and other Arabian Gulf states have made no concerted efforts in initiating similar programs. The author emphasizes the need for cooperation in catalogingespecially of local materials. Due to unavailability of cataloging copy from the Library of Congress and other sources for a high percentage of imprints from Arab countries, and in the absence of bibliographic cooperation, libraries are doing redundant cataloging and thus wasting both time and money. The author reviews the current state of bibliographic cooperation, discusses prospects for further cooperation, and highlights difficulties in cooperation. The author concludes with recommendations that King Fahd National Library develop a national cooperative cataloging program with specific goals, set guidelines, and prepare rules and procedures for participating libraries to contribute in various cooperative cataloging programs in the Kingdom of Saudi Arabia.

O through the joint action of a group of independent libraries which make the bibliographic records accessible to group members and sometimes to non-participating libraries as well. Sometimes called shared cataloging because the cataloging responsibility and cataloging product are shared" (ALA $1983,59)$. The driving force for cooperative cataloging in North America has been to reduce cataloging costs. Librarians were as much concerned about the cataloging cost in 1885 when it was just
$\$ 0.3575$ (Tillett 1993) per item as they are now when it is $\$ 48$ (Allan 1990). The cost factor becomes even more serious when it is expended over and over again in libraries for the same title. For example, if one hundred libraries acquire the same title and catalog it at an average cost of $\$ 48$, the libraries together would spend $\$ 4,800$ to catalog a single title. The other reasons that warranted bibliographic cooperation were the growing backlog of uncataloged materials and the lack of catalogers with language expertise or adequate training.

Impressed by the success of various

ZAHIRUDDIN KHURSHID (khurshid@dpc.kfupm.edu.sa) is Senior Manager, Cataloging Operations Division, and Acting Library Systems Analyst, King Fahd University of Petroleum and Minerals Library, Dhahran, Saudi Arabia. This is a revised version of a paper presented at the Third SLA/AGC Conference on Strengthening Resource Sharing in Libraries and Information Centers in the Arabian Gulf region, Al-Ain, United Arab Emirates, March 15-17, 1995. Manuscript received March 17, 1997; accepted for publication May 2, 1997. 
cooperative cataloging programs in North America, and especially the success of computerized networks, libraries in other parts of the world have built upon, and perhaps even improved, the North American model (Holley 1993). The bibliographic networks in Europe, Australia, and New Zealand are renowned for their shared cataloging activities. But the situation in Asia in general and the Arabian Gulf region in particular is not very encouraging. The prospects and problems of cooperative cataloging in Saudi Arabia discussed in this article can be generalized to the entire region.

\section{Bibliographic Cooperation in Saudi Arabia}

Saudi Arabia has achieved phenomenal development in all socioeconomic sectors during the last twenty-five years. The government has spent huge sums of money to develop human resources by providing free education to its citizens from primary level to graduate level and beyond. The education program is well supported by physical facilities-including libraries. All seven university libraries have developed information resources in support of their academic programs. Both government and private organizations have established over 40 special libraries to fulfill information needs of the community in business, commerce, and industry. According to the author of one recent survey (Abbas 1994), there are 69 public libraries throughout the kingdom, of which 59 are controlled by the General Directorate of Public Libraries under the Ministry of Education. The rest are controlled by other ministries.

Several academic and special libraries are currently undertaking automation projects, and at least one academic library at King Fahd University of Petroleum and Minerals (KFUPM) is fully automated. However, if we review the numerous articles written on the state of libraries and librarianship in Saudi Arabia, we find that most authors have talked about the lack of cooperation among libraries (Khurshid 1979; Line 1983; Ashoor 1989). Each library has generally followed its own course in achieving the goal of collection building, automation, library services, etc. Not only have the individually projected goals not been achieved, but duplication of effort has wasted a great deal of time and money. While there is a comprehensive need for cooperation in each area of library activity, I will attempt to address a more pressing need for bibliographic cooperation in Saudi Arabia and how it can be achieved.

The collections of libraries in Saudi Arabia in general are comprised mostly of Arabic materials. Cataloging copy for about $75 \%$ of Arabic materials is not available from any sources, local or external. The following statistics show the representation of various language materials in CDMARC Bibliographic, the Library of Congress database of approximately five million Machine-Readable Cataloging (MARC) records on CD-ROM. Arabic records form less than $1 \%$ of the entire database:

$$
\begin{array}{lr}
\text { English } & 3,205,798 \\
\text { French } & 348,630 \\
\text { Spanish } & 288,388 \\
\text { Italian } & 126,227 \\
\text { Arabic } & 34,750
\end{array}
$$

The average number of Arabic records added to the CDMARC Bibliographic database every year (based on a ten-year period, 1986-95) is 1,107, which represents approximately $12 \%$ of the Arabic titles produced in the entire Arab world (United Nations 1995; International Marketing Data and Statistics 1996). Aside from representing a small percentage of Arabic records, CDMARC Bibliographic (or for that matter any other Western database) has two additional problems. First, the Arabic records are presented in romanized (transliterated in English) form, which is not acceptable to Arabian local users and therefore generally not used by Arab libraries. Second, Arab libraries use their own name and subject headings, which means cataloging copy from external sources would require a great deal of changes in headings.

It is clear from the above facts that the cataloging copy of Arabic materials available from external sources is not only limited but also is not fully compatible with 
local cataloging practices. That is why the percentage of original cataloging of Arabic materials in Saudi libraries is around $90 \%$. In the absence of any shared cataloging program, each library is doing its own cataloging of many titles that have been cataloged by other libraries.

\section{Current State of Cooperation}

There has always been some awareness among Saudi libraries about the need for shared cataloging, but it did not bring about any tangible results. The primary reason is the absence of a forum or an agency that could initiate, organize, and coordinate the activities. However, some activities have been initiated by a few individual libraries as well as one group of libraries, which can be considered as forerunners of bibliographic cooperation in Saudi Arabia. Of them the three major activities are discussed below.

1. Cataloging-in-Publication. Several publishers are currently providing Cataloging-in-Publication (CIP) data with their publications. Notable among them are the university presses of King Abdulaziz University, King Saud University, Imam Mohammad Ibn Saud University, and Umm Al-Qura University. The CIP data included in university publications are generally prepared by the library staff of the respective universities. Although the number of publications with the CIP data produced by these presses is quite small, it still helps to reduce the expense of redundant cataloging.

The most significant development that has taken place in the area of CIP in recent years is the assignment of a new role to King Fahd National Library (KFNL) in Riyadh as the central agency in preparing CIP for books published in Saudi Arabia. The national library was created in 1990 through a royal decree. The library is governed by a Trustee Council consisting of a chairman and five members. While the members are appointed by the King, the council appoints the director, who is responsible for administering the library in the light of the goals set by the council. Before KFNL assumed its recent role, only a small group of publishers-including the university presses - were preparing CIP data. The KFNL has hired some Arabic and non-Arabic catalogers to cope with the increasing amount of CIP cataloging. (Non-Arabic catalogers are generally hired from India and Pakistan and can read Arabic but may have difficulty in understanding and speaking Arabic. They are normally responsible for cataloging non-Arabic materials because of their English-language skills.) If the publishers throughout the kingdom cooperate by sending the title page and preliminaries of books nearing publication to the National Library so that preliminary cataloging data can be prepared, it can bring about the same results as have been produced by the CIP program of the Library of Congress.

According to a survey, the CIP program saved the U.S. libraries an estimated $\$ 1.15$ billion in 1990 by providing authoritative and timely bibliographic access to materials that libraries otherwise would have had to catalog themselves (Thomas and Younger 1993). No such survey has been done in Saudi Arabia to estimate the national saving from the CIP program of the KFNL. However, the program is growing quickly, and with the increasing participation of all major publishers of Saudi Arabia in the program, it is expected that approximately $80 \%$ of the titles produced in the kingdom (between 350 to 400 titles per year) will include CIP data, thus saving the Saudi libraries approximately $\$ 1$ million a year (the cost of 400 common titles cataloged in fifty libraries at an average cost of $\$ 50$ per title).

Another important benefit of the program will be the possible improvement in the quality of cataloging, which has been poor due to 
nonadherence to cataloging standards by libraries and the lack of qualified and trained catalogers.

2. Remote access to online catalogs. In the early 1980s, a few libraries started automation projects, and by the end of the decade sixteen Saudi libraries had been engaged to a varied extent in automation enterprises (Al Dosary and Ekrish 1991). DOBIS/LIBIS and MINISIS are the most widely used software packages. In fact, there are five users of DOBIS/LIBIS (excluding Umm Al-Qura University [UQU], which leased DOBIS/LIBIS in 1986 but has not yet installed it) and an equal number of users of MINISIS. Some libraries are using in-house-developed software.

Of the libraries engaged in automation, $75 \%$ have online catalogs in operation, and all of them have created databases ranging in size from a few thousand records to more than 300,000 . Although there has been no exchange of records between automated libraries, the possibilities of exchange do exist-at least among the libraries that have the same system. Some years back a couple of DOBIS/LIBIS user libraries approached the KFUPM Library with a request to allow them to import KFUPM records into their local databases. The KFUPM Library could not accept this request for the reason that about $60 \%$ of its records were downloaded from the LC MARC tapes, and copyright regulations do not allow libraries to redistribute LC MARC records. However, the library was and is still willing to exchange records created locally. Last year, as a result of several years of discussions between three DOBIS/LIBIS user libraries (King Abdulaziz, King Fahd, and King Saud Universities), an arrangement was made to provide remote access to the online catalog of each library from the other two. As of 1996, the KFUPM Library online catalog was accessible from King $\mathrm{Ab}$ dulaziz and King Saud University Li- braries. However, the KFUPM Library has access to the King Saud University Library catalog only. Access to the King Abdulaziz University Library catalog will, it is hoped, be available soon.

The database of these three large libraries together can provide access to more than half a million records, which include duplicate and triplicate records for approximately $30 \%$ of the titles (identified in accessions lists of the three libraries) that are available in all the three libraries. If the libraries were to engage in shared cataloging via remote access to their respective catalogs, there could be a significant drop in the original cataloging needed by each library.

3. Access to KACST bibliographic databases through Gulfnet. Gulfnet is a computer network established by King Abdulaziz City for Science and Technology (KACST) in Riyadh, Saudi Arabia. It was started in May 1985 to facilitate exchange of data, information, and programs for use by scientists, researchers, librarians, and information professionals in Saudi Arabia and the Gulf states. At present 11 universities and research centers in Saudi Arabia, Kuwait, and Bahrain are connected to Gulfnet through public leased telephone lines. There is also a dial-up communication network, KACSTNET, which connects 60 research institutions and libraries in the kingdom with the central computer at KACST.

Among the services offered by the network is the searching of various databases, including a union list of serials and the KACST library cata$\log$. The union list of serials database was developed by KACST and contains 20,000 titles held by academic and research libraries in Saudi Arabia. It has become a primary source of locating materials for interlibrary loan. Another online union list of Arabic periodicals held by university libraries of Saudi Arabia is under preparation. The KACST library 
catalog (which can be searched through Gulfnet and KACSTNET) provides information about the KACST collection, which includes over 11,000 books, 350,000 technical reports on microfiche, and over 60,000 source documents relating to the national databases produced by KACST (Al-Tasan 1992).

The use of Gulfnet to share cataloging data has been very limited. Only the KACST catalog is available for searching by member libraries. Access to catalogs of other libraries is not yet available, and there is not much hope that Gulfnet services will be expanded further once full Internet connectivity becomes available in the kingdom.

\section{Prospects for Further CoOperation}

The current state of cooperative cataloging reviewed in the preceding section cannot be considered satisfactory. The programs have been undertaken in isolation and are very limited in scope. In developing these programs, no efforts seem to have been made to learn from the experiences of cooperative cataloging programs developed by Western libraries. Some of the renowned programs might produce similar results if adapted to local requirements. In the following section, we will discuss the prospects for developing cooperative cataloging programs in the Kingdom of Saudi Arabia.

\section{UNION CATALOGS}

As mentioned earlier, DOBIS/LIBIS and MINISIS are the two major systems currently in use in Saudi Arabia. Of the two systems, DOBIS/LIBIS has excellent capabilities for networking, which have not been fully exploited. The DOBIS/LIBIS network structure allows participating libraries to share a union catalog in which a record will be created once by the library that first acquired an item. If copies of the same item are acquired by other libraries, they can either add their location information to the existing bibliographic record, or they can create a separate file of local copies.

Of the five DOBIS/LIBIS user libraries, the KFUPM Library is in the best position to act as the central node in the network. It has highly qualified and motivated staff who can prepare quality records and also review and upgrade the quality of records from participating libraries according to international standards. The "correct cataloging" subfunction of DOBIS/LIBIS can allow authorized catalogers to review and correct catalog entries of other catalogers who have lower authorization levels (Khurshid 1994).

Another union catalog can be developed by MINISIS user libraries with the central node at KFNL. This library is best suited to be the central node because most of the libraries that use MINISIS are located in Riyadh, which would make communication easier between member libraries and the central node. This does not mean that communication with the central node cannot be made from remote locations. However, that would require high-speed communication lines as well as some additional hardware.

If the new versions of DOBIS/LIBIS and MINISIS support the Z39.50 protocol, then it would be possible to link the two union catalogs and expand the scope of the database for cooperative cataloging. While the successor product of DO$\mathrm{BIS} / \mathrm{LIBIS}$ is expected to have Z39.50 support, we do not know whether future versions of MINISIS will provide this support.

\section{National Bibliographic AgEnCY}

Each country in the Gulf region is expected to create a National Bibliographic Agency (NBA) as an integral part of the national library or as an independent agency with the responsibility for preparing authoritative and comprehensive bibliographic records for all new publications issued in the country. They are further expected to create those records in accordance with accepted bibliographic standards (IFLA 1979). King Fahd National Library is already carrying out some of the tasks of a national 
bibliographic agency, such as preparing a national bibliography and CIP data. However, in order for libraries to take advantage of these services, some improvements need to be made. These include:

1. The National Library should distribute its cataloging records in machinereadable form so that libraries can download them into their local systems and save time and money.

2. The National Library should implement a comprehensive legal deposit system so that the library gets each and every title published or issued (in all languages and formats) in the country. This will also increase the availability of cataloging copy of local materials.

3. The CIP program should be expanded to include publications from all major publishers-including those from university presses. This would especially benefit small libraries, which cannot make use of machine-readable records due to lack of computer infrastructure.

\section{ACCess to Online Catalogs THROUGH THE INTERNET}

Saudi Arabia is expected to join the Internet soon with a central node at KACST in Riyadh. Among the numerous information resources available on the Internet are hundreds of online catalogs of academic and special libraries that offer opportunities for any library catalog to be treated as a bibliographic utility. Following the example of Western libraries, the libraries in Saudi Arabia could offer their catalogs on the Internet both for use by local libraries for cataloging and for locating materials for interlibrary loan. Those libraries that cannot make their catalogs available on the Internet could at least make them accessible through dedicated or dial-up lines.

\section{Difficulties in Cooperation}

There are some difficulties that must be overcome in order for cooperation to work successfully.

1. Leadership. To start a nationwide co- operative cataloging program, a strong central agency is needed that can provide leadership to the libraries participating in the program. Being a national agency, KFNL is in a better position to provide this leadership. In addition to acting as a depository library of all Saudi publications, it has a mandate to compile a national bibliography, prepare CIP data, assign ISBN and ISSN numbers, etc. To carry out these and other activities, the library must muster the support of all libraries that can make effective contributions to the program. The Library of Congress provides an excellent model of leadership for any national agency that aims to engage in a cooperative cataloging program.

2. Standardization. The cataloging records produced by the participating libraries in a cooperative program must be consistent, which requires application of standards. While all libraries claim to follow standards in preparing records, the real situation is quite different. Authors of a KFUPM study in 1987 revealed serious inconsistencies in the cataloging practices of university libraries of Saudi Arabia (Khurshid 1988). The libraries did not fully adhere to cataloging standards. Librarians at several libraries have modified, revised, or interpreted cataloging rules to satisfy local needs. There is no coordination among them to prepare nationallevel standards.

Whatever standards have been prepared are mostly individual efforts and are out-of-date. For example, the Arabic subject headings list prepared by Swaydan (1985) and adopted by all university libraries in Saudi Arabia as a standard list has not been revised since its first publication. As a result, many libraries have taken liberty in adding subject headings for new disciplines on their own -without consulting or notifying other libraries.

Another problem in the area of standardization is the absence of a 
national MARC format for the exchange of bibliographic information. At present libraries are using a variety of formats, including USMARC, extended USMARC, and locally developed MARC. In the case of non-Arabic data, DOBIS/LIBIS and MINISIS user libraries are using interface programs to import bibliographic records from Western sources. These programs might facilitate exchange of records between libraries having the same system. However, the exchange of records between libraries with different systems has been a real problem. How this problem can hamper the progress of a cooperative program can be seen in the case of the KACST union list of serials project. When the project was initiated in 1985, the KFUPM Library and some other automated libraries provided their serials records in machine-readable form, but they could not be loaded into the KACST system because of incompatibility with the KACST record format. As a result, KACST had to rekey these records into their system manually. Updating this list is also difficult for the same reason.

The lack of a national MARC format that handles Arabic script is yet another part of the problem. Many libraries have either modified the original software, for example DOBIS/LIBIS, or have developed inhouse programs to create Arabic records. These programs are not compatible with the Arabic script program developed by the Research Libraries Information Network (RLIN) and therefore cannot accept records from the RLIN database or from the Library of Congress, which also uses the RLIN program to cata$\log$ Arabic materials.

The development of the system at RLIN to record titles in both the romanized and Arabic script (which was underwritten by the Kuwait Foundation for the Advancement of Sciences) did not gain acceptance as a standard system by Arab libraries for two reasons. First, it treats Arabic information and its romanization as paired fields, and second, it places the romanized data before the original script representation in an online record. In the USMARC equivalent of the same record, the romanized data are given in a regular field and their alternate graphic representation in an 880 field, with a subfield 6 in each field to create a link between them (Aliprand 1992).

Arab librarians do not wish to see Arabic information in script form subordinated to romanization in an online record; rather they would prefer to see the complete record in their own script. They feel that instead of asking Western agencies to prepare a MARC format to accommodate Arabic script for them, they should come forward and prepare their own format. In this regard librarians at the KFUPM Library prepared a study in 1994 to review the current state of Arabization by individual libraries and institutions at local, regional, and international levels and to seek answers to several questions that will help to provide the framework for developing an ARABMARC (AlMuhtaseb, Ashnoor, and Khurshid 1994). Further progress in this area depends on the willingness of a national or regional organization to coordinate or provide funding for the project.

The use of a varied array of character sets in commercial applications, such as ASMO 449 in DOBIS/LIBIS and MINISIS, and an RLIN extended Arabic character set in VTLS will continue to be a major problem in the exchange of Arabic data unless software vendors decide to adopt Unicode as a common standard. Unicode might not be a perfect standard for processing Arabic characters, but it can be improved through participation of individuals as well as libraries from Arab countries. Unfortunately no one from Saudi Arabia or the Gulf 
region is known to have been participating in the development of Unicode. Unicode may also be a better solution for Arab libraries that are currently addressing the issue of the Arabic character set to be implemented in ARABMARC.

\section{Telecommunications and computer} infrastructure. Cooperative cataloging requires a certain level of telecommunications and computer infrastructure (Holley 1993). This level has not been fully achieved in Saudi Arabia. The telecommunication system in particular is not well developed. As a result, libraries are not taking full advantage of Internet resources. The Internet is being used in cooperative cataloging projects in the United States both to communicate in a timely fashion between librarians and to access catalog records in other online catalogs (McCombs 1994). Without the Internet or other telecommunications networks, libraries in Saudi Arabia cannot achieve much success in bibliographic cooperation.

The present communication link among libraries in Saudi Arabia is very limited and is through dedicated or dial-up lines, which are slow and not very reliable. This also hampers any computerized cooperative cataloging program in the country, which requires quick access to information and the exchange of large amounts of bibliographic data between libraries. Except for most university and special libraries, which have mini- or mainframe systems, other libraries do not have the level of computer infrastructure that is essential for participating in computerized cooperative cataloging programs. This level needs to be improved before any national-level cooperative pro. gram is implemented.

Having reviewed the prospects for and difficulties in bibliographic cooperation, it is appropriate to highlight the major steps that need to be taken to make the cooperation work successfully. The national library should implement the legal deposit comprehensively, expand the CIP program, develop and adopt cataloging standards including the ARABMARC format, and prepare and distribute records in machine-readable form. Telecommunications and the computer infrastructure should be improved to allow libraries to provide remote access to their online catalogs through Gulfnet and dial-up lines and eventually through the Internet once full connectivity becomes available in the kingdom.

\section{Conclusion}

The vision of cooperative cataloging in Saudi Arabia should parallel that established in other countries: "to put into place the necessary support to catalog, once and only once, every item owned or made accessible by libraries and to share that information with all others who need it (Thomas and Younger 1993, 257). Librarians in Saudi Arabia and elsewhere in the Gulf region have some understanding of the advantages of cooperative cataloging programs. But they do not have a clear idea about how these programs can be developed and implemented and in what way they can participate in these programs. It would therefore be appropriate for a national agency-preferably King Fahd National Library together with some notable academic and special libraries in the kingdom-to initiate a program similar to the renowned Program for Cooperative Cataloging (PCC) of the United States, with a clear mission and goals. The Saudi Arabian PCC equivalent could set guidelines and prepare rules and procedures for participating libraries to contribute through various programs, including the creation of bibliographic databases, union lists of serials, Arabic name authorities databases, etc. The bibliographic component of the program could also define a core-level bibliographic record containing a uniform level of detail, as is done by the PCC. The scope of the program could be widened to develop a set of Arabic cataloging standards for preparing uniform records (including the ARAB- 
MARC format), provide training, and seek funds to support cooperative library projects in Saudi Arabia and in the entire Gulf region.

\section{Works CITED}

Abbas, Hisham A. 1994. Public libraries in Saudi Arabia. In Information and libraries in the Arab world, 140-54. London: Library Association Publishing.

Al Dosary, Fahad M., and Abdurrahman H. Ekrish. 1991. The state of automation in selected libraries and information centers in Saudi Arabia. Libri 41: 109-20.

Aliprand, Joan M. 1992. Arabic script on RLIN. Library hi tech 10: 59-80.

Allan, Ann, 1990. Chasing MARC: Searching" in BiblioFile, Dialog, OCLC, and RLIN. Journal of academic librarianship 15:33943.

Al-Muhtaseb, Husni, M. Saleh Ashoor, and Zahiruddin Khurshid. 1994. A step towards Arabic machine-readable cataloging (ARABMARC). Paper presented at the Second Arabian Gulf Chapter, Special Libraries Association Conference, Bahrain, Jan. 12-14, 1994.

Al-Tasan, Mohammed Ali. 1992. The role of the King Abdulaziz City for Science and Technology in information services in the Kingdom of Saudi Arabia. Journal of information science 18: 491-95.

American Library Association. 1983. The ALA glossary of library and information science. Chicago: ALA.

Ashoor, M. Saleh. 1989. Bibliographic networking in the Arabian Gulf region: Prospects and problems. Resource sharing \& information networks 4: 13-25.
Holley, Robert P. 1993. Cooperative cataloging outside North America: Status report 1993. Cataloging o classification quarterly 17: 201-36.

IFLA International Office for UBC. 1979. Guidelines for the national bibliographic agency and the national bibliography. Paris: Unesco.

International marketing data and statistics. 1996. London: Euromonitor.

Khurshid, Zahiruddin. 1979. Libraries and information centers in Saudi Arabia. International library review 11: 409-19.

1988. Cataloguing practices in university libraries of Saudi Arabia. International cataloguing and bibliographic control 17 : $59-61$.

1994. DOBIS/LIBIS network of university libraries in Saudi Arabia. Resource sharing \& information networks 9: 10110.

Line, Maurice B. 1983. Libraries in Saudi Arabia: Some reflections. International $l i$ brary review 15: 365-73.

McCombs, Gillian M. 1994. The Internet and technical services: A point break approach. Library resources \& technical services 38 : 169-77.

Swaydan, Nasser M. 1985. Arabic subject headings, 2d ed. Riyadh: King Saud Univ.

Thomas, Sarah E., and Jennifer A. Younger. 1993. Cooperative cataloging: A vision for the future. Cataloging \& classification quarterly 17: 237-57.

Tillett, Barbara B. 1993. Catalog it once for all: A history of cooperative cataloging in the United States prior to 1967 (before MARC). Cataloging \& classification quarterly 17: 3-38.

United Nations. 1995. Statistical yearbook. New York: UN. 